\title{
Adverse drug reactions and drug-drug interactions with over-the-counter NSAIDs
}

\author{
This article was published in the following Dove Press journal: \\ Therapeutics and Clinical Risk Management \\ 15 July 2015 \\ Number of times this article has been viewed
}

\author{
Nicholas Moore' \\ Charles Pollack ${ }^{2}$ \\ Paul Butkerait ${ }^{2}$ \\ 'Department of Pharmacology, \\ Université de Bordeaux, Bordeaux, \\ France; ${ }^{2}$ Pfizer Consumer Healthcare, \\ Madison, NJ, USA
}

\begin{abstract}
Nonsteroidal anti-inflammatory drugs (NSAIDs) such as ibuprofen have a long history of safe and effective use as both prescription and over-the-counter (OTC) analgesics/ antipyretics. The mechanism of action of all NSAIDs is through reversible inhibition of cyclooxygenase enzymes. Adverse drug reactions (ADRs) including gastrointestinal bleeding as well as cardiovascular and renal effects have been reported with NSAID use. In many cases, ADRs may occur because of drug-drug interactions (DDIs) between the NSAID and a concomitant medication. For example, DDIs have been reported when NSAIDs are coadministered with aspirin, alcohol, some antihypertensives, antidepressants, and other commonly used medications. Because of the pharmacologic nature of these interactions, there is a continuum of risk in that the potential for an ADR is dependent on total drug exposure. Therefore, consideration of dose and duration of NSAID use, as well as the type or class of comedication administered, is important when assessing potential risk for ADRs. Safety findings from clinical studies evaluating prescription-strength NSAIDs may not be directly applicable to OTC dosing. Health care providers can be instrumental in educating patients that using OTC NSAIDs at the lowest effective dose for the shortest required duration is vital to balancing efficacy and safety. This review discusses some of the most clinically relevant DDIs reported with NSAIDs based on major sites of ADRs and classes of medication, with a focus on OTC ibuprofen, for which the most data are available.
\end{abstract}

Keywords: adverse effects, nonsteroidal anti-inflammatory drugs, gastrointestinal, cardiovascular, renal

\section{Introduction}

Cyclooxygenase (COX) inhibitors, commonly called nonsteroidal anti-inflammatory drugs (NSAIDs), such as ibuprofen, diclofenac, and naproxen, have anti-inflammatory and analgesic/antipyretic properties across a wide range of dosing regimens. Prescription-strength NSAIDs are effective for relief of chronic musculoskeletal pain and inflammation in conditions such as rheumatoid arthritis (RA) or osteoarthritis (OA).${ }^{1,2}$ Lower, over-the-counter (OTC) doses of NSAIDs are effective for short-term (eg, $\leq 10$ days) relief of minor aches and pains due to headache, toothache, backache, menstrual cramps, common cold, muscular aches, and arthritis. ${ }^{3}$ NSAIDs taken at OTC doses can also be effective at relieving painful episodes in patients with chronic diseases such as OA. ${ }^{4}$ Ibuprofen is an NSAID with a long history of safe and effective use at both prescription (maximum 2,400-3,200 mg/d) and OTC ( $<1,200 \mathrm{mg} / \mathrm{d}$ ) doses. ${ }^{3,5}$ Single-dose studies using OTC doses have confirmed that ibuprofen (400 mg) provides superior analgesic efficacy to acetaminophen (1,000 mg). ${ }^{6,7}$

All NSAIDs inhibit COX, an enzyme that converts arachidonic acid to prostaglandins, thereby mediating pain, inflammation, and fever. In the process, 
prostaglandin $\mathrm{H}_{2}$ is converted to five primary prostaglandins, including thromboxane $\mathrm{A}_{2}$ (which stimulates platelet aggregation and blood clot formation) in platelets and prostacyclin (a vasodilator that inhibits platelet aggregation) in the endothelium. ${ }^{8}$ Two COX isoenzymes (COX-1 and COX-2) are commonly recognized. In general, COX-1 is constitutively expressed and is involved in gastroprotection from stomach acid and in thromboxane formation by platelets. COX-2 is inducible by inflammatory mediators in a wide range of tissues and has been associated with inflammation; however, it may also be constitutively expressed, where it contributes to renal physiology, reproductive function, bone resorption, and neurotransmission. ${ }^{8}$

Drug-drug interactions (DDIs) have been reported when NSAIDs are coadministered with some common medications, and these DDIs can be classified in several ways. DDIs may result from pharmacokinetic interactions (ie, alterations in drug absorption, volume of distribution, metabolism, or excretion), pharmacodynamic interactions (ie, additive, synergistic, or antagonistic effects that occur despite unaltered plasma levels of the drugs), pharmaceutical incompatibility (eg, combinations of acids and bases), a combination of these mechanisms, or other unknown mechanisms. ${ }^{9}$ One type of pharmacokinetic DDI of relevance to NSAIDs occurs when one highly protein-bound drug (eg, NSAID) competes for binding sites with other protein-bound drugs in the plasma..$^{910}$

When assessing the safety profile of NSAIDs, it is important to distinguish between prescription and OTC use, especially since many adverse drug reactions (ADRs) are dose related. ${ }^{11}$ Prescription users typically use highdose NSAIDs for prolonged periods and are monitored for ADRs on a regular basis by health care providers. In contrast, although risks are generally lower with occasional use of OTC NSAIDs, users of these products are not routinely monitored by a health care provider and may be at risk for unrecognized ADRs. In addition, although a majority of consumers use OTC NSAIDs as per labeled instructions, a small proportion may exceed recommended doses,${ }^{12}$ likely resulting in the intake of prescription-level doses, the safety profile of which has also been well characterized.

This review discusses some of the most clinically relevant DDIs reported with NSAIDs based on major sites of ADRs and classes of medication, with a focus on OTC ibuprofen, the most commonly used OTC NSAID. ${ }^{11}$ Fewer studies are available regarding ADRs and DDIs with other OTC NSAIDs (eg, naproxen, ketoprofen, diclofenac); these data have been included where available. It is likely that the interactions described for ibuprofen apply to these other NSAIDs as well, since they share the same mechanism of action and many of the same pharmacologic properties (with the exception of their degree of affinity for COX-1 vs COX-2). Given the low doses and short-term use of all OTC NSAIDs, risks of DDIs are generally much lower than for the corresponding full prescription dosages of these agents.

\section{Major sites of ADRs}

ADRs associated with NSAIDs primarily manifest in gastrointestinal (GI), cardiovascular (CV), and renal sites.

\section{Gl effects}

GI complications are well-recognized risks of NSAIDs as a class and vary by the respective NSAID used as well as by dose (ie, higher doses $=$ more GI risk). ${ }^{13-16}$ Aspirin increases bleeding risk, even at low cardioprotective doses (eg, 75-300 $\mathrm{mg}) .{ }^{17,18}$ In terms of nonselective NSAIDs, a meta-analysis of data from three retrospective case-control studies found that ibuprofen had the lowest odds ratio (OR) for development of GI bleeding versus diclofenac, naproxen, piroxicam, and indomethacin, but that the OR increases with dose level for each agent (Figure 1). ${ }^{19}$

The Paracetamol, Aspirin, and Ibuprofen New Tolerability (PAIN) study $(\mathrm{N}=8,677)$ assessed the frequency of significant adverse events (AEs) associated with OTC analgesic dosing in patients with acute pain..$^{20}$ In this study, a significant AE was defined as any event that was serious, severe, or moderate; necessitated a second physician consultation; led to treatment discontinuation; or was of missing intensity. The PAIN study demonstrated that OTC ibuprofen $(\leq 1,200 \mathrm{mg} / \mathrm{d})$ was similar to acetaminophen $(\leq 3,000 \mathrm{mg} / \mathrm{d})$ in terms of the incidence of significant AEs ( $13.7 \%$ vs $14.5 \%$, respectively), but that statistically significantly fewer such events occurred with ibuprofen in comparison with aspirin $(\leq 3,000$ $\mathrm{mg} / \mathrm{d}, 18.7 \% ; P<0.001)$ during $1-7$ days of treatment. ${ }^{20}$ As expected, rates of GI AEs were significantly lower in patients receiving OTC doses of ibuprofen versus aspirin $(4.0 \%$ vs $7.1 \% ; P<0.001)$, and interestingly, ibuprofen was noted to produce significantly fewer overall GI AEs vs acetaminophen $(5.3 \% ; P=0.025){ }^{20}$ The PAIN study also identified numerous factors associated with increased risk of AEs, including female sex, older age, height $\leq 160 \mathrm{~cm}$, use of the analgesic for musculoskeletal pain (vs menstrual cramps, sore throat, toothache, or fever), 


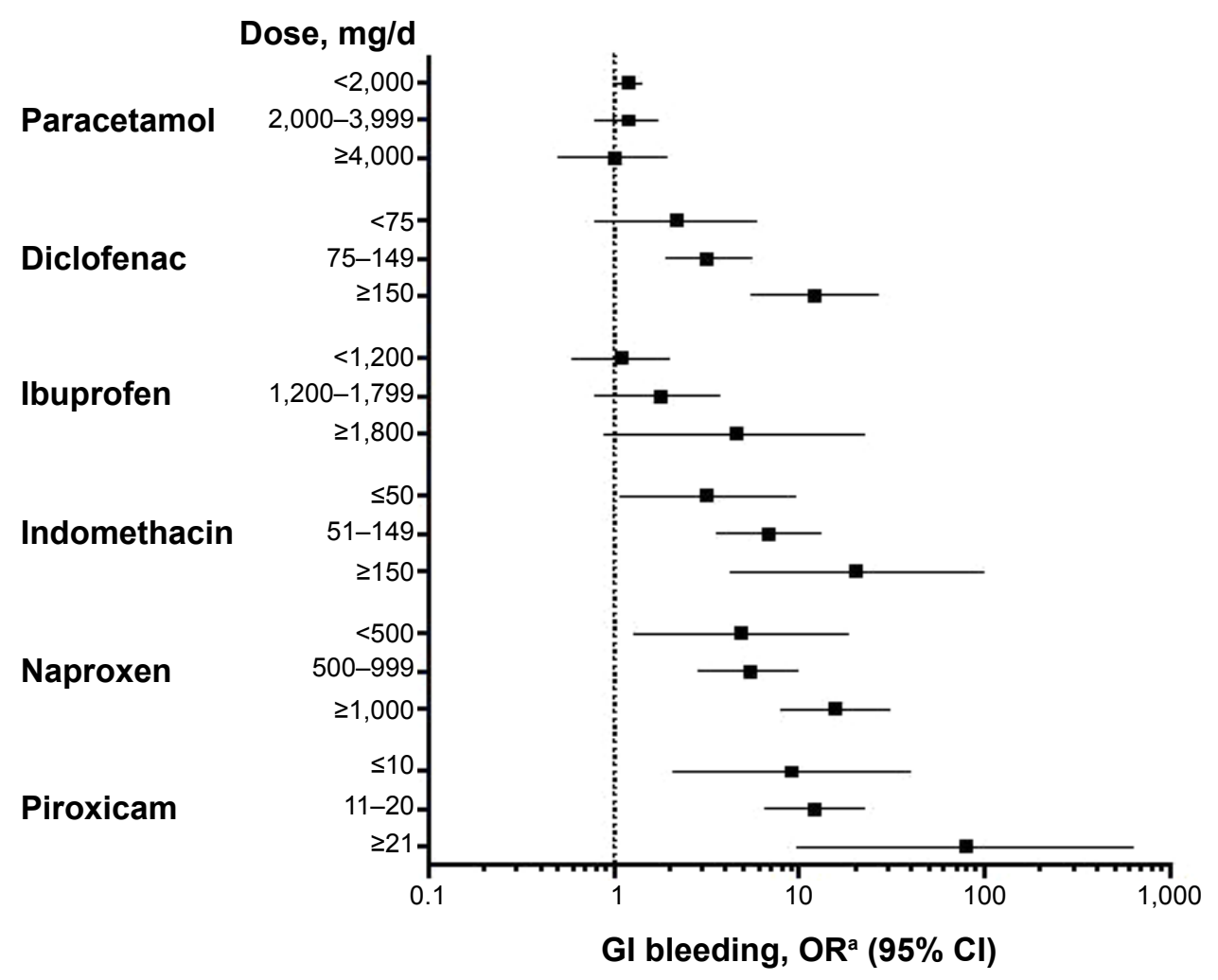

Figure I Effect of dose (in week before index day) on ORs of upper GI bleeding: meta-analysis of three case-control studies.

Notes: ${ }^{a}$ All ORs are relative to nonuse of any non-aspirin nonsteroidal anti-inflammatory drug or aspirin and are adjusted for use of aspirin, ketoprofen, anticoagulants, smoking, and history of upper GI problems. Copyright (c) 2002, John Wiley and Sons. Adapted with permission from Lewis SC, Langman MJ, Laporte JR, Matthews JN, Rawlins MD, Wiholm BE. Dose-response relationships between individual nonaspirin nonsteroidal anti-inflammatory drugs (NANSAIDs) and serious upper gastrointestinal bleeding: a meta-analysis based on individual patient data. Br J Clin Pharmacol. 2002;54(3):320-326. ${ }^{19}$

Abbreviations: $\mathrm{Cl}$, confidence interval; $\mathrm{Gl}$, gastrointestinal; OR, odds ratio.

concomitant use of prohibited medications, and increasing number of concomitant medications..$^{21}$

The prospective, observational Arthritis, Rheumatism, and Aging Medical Information System database study evaluated the GI toxicity of ibuprofen, aspirin, and acetaminophen at various doses in patients with $\mathrm{RA}(\mathrm{n}=5,692)$ or OA $(n=3,124)$ and found no GI toxicity rates of $>1 \%$ when each respective agent was taken alone, especially when used occasionally or intermittently at lower doses. ${ }^{22}$ Interestingly, the investigators found that rates of GI events were significantly higher $(P<0.05)$ in the acetaminophen group taking concurrent therapy plus corticosteroids compared with those taking either ibuprofen or aspirin with concurrent therapy plus corticosteroids. ${ }^{22}$

In comparisons of GI AEs among NSAID users, results from several meta-analyses further support a lower risk of GI AEs with ibuprofen compared with other NSAIDs. ${ }^{15,16,19,23}$ For example, Richy et al reported a lower relative risk (RR) for GI complications with ibuprofen $(1,200 \mathrm{mg} / \mathrm{d}$ median dose; RR: 1.19 ; $95 \%$ confidence interval [CI]: $0.93-1.54$ vs no NSAID use) than with other NSAIDs, including naproxen
( 875 mg/d median dose; RR: 1.83 ; 95\% CI: $1.25-2.68$ vs no NSAID use) ${ }^{23}$ A case-control study ( $\mathrm{N}=1,217 ; 627$ cases with GI bleeding and 590 controls) found that GI bleeding risk increased dose dependently by current ibuprofen use (OR: 1.8 ; $95 \%$ CI: $0.8-4.1$ for $\leq 600 \mathrm{mg} / \mathrm{d}$; OR: $3.5 ; 95 \%$ CI: $1.2-10.7$ for $601-1,200 \mathrm{mg} / \mathrm{d}$; and OR: $3.9 ; 95 \% \mathrm{CI}$ : $1.2-12.9$ for $>1,200 \mathrm{mg} / \mathrm{d}$ ). ${ }^{24}$

In addition to strength of dose, length of treatment also contributes to GI risk. Lewis et al interviewed 359 persons admitted to hospitals in the Philadelphia, PA, USA, area, and 1,889 randomly telephoned controls for serious GI toxicity to evaluate the potential contribution of OTC NSAIDs to GI toxicity. They found no association of infrequent use (13 days in the index week) of OTC NSAIDs with serious upper GI toxicity (OR: 0.67 ; 95\% CI: $0.43-1.06$ ), but the association was significant when OTC NSAIDs were used 4-7 days in the index week (OR: 1.83; 95\% CI: 1.14-2.95). ${ }^{25}$

Concomitant medications also influence the risk of GI events among NSAID users. The risk of upper GI events is increased when non-aspirin NSAIDs are combined with aspirin, but this increase in risk may be ameliorated when 
NSAIDs are used concurrently with ulcer-healing drugs (ie, proton pump inhibitors). ${ }^{26}$

\section{CV risk}

All non-aspirin NSAIDs may be associated with a potential increase in CV thrombotic risk. ${ }^{27}$ A US Food and Drug Administration (FDA) Advisory Committee (February 10-11, 2014) concluded that there is insufficient evidence to support claims of difference among NSAIDs with regard to CV risk. ${ }^{28}$ Labeling for OTC NSAIDs currently states, "the risk of heart attack or stroke may increase if you use more than directed or for longer than directed. ${ }^{29,30}$ However, the FDA Advisory Committee concluded that there is no period of latency for $\mathrm{CV}$ thrombotic risk, and therefore, patients should take the lowest dose of NSAIDs for the shortest period of time possible. ${ }^{28}$

A majority of the data on CV risk among NSAID users is from epidemiological studies of prescription NSAIDs. COX-2 inhibitors were developed as prescription NSAIDs with lower GI risks, but some have been posited to have increased $\mathrm{CV}$ risk. ${ }^{31,32}$ In studies evaluating potential risk for $\mathrm{CV}$ events (myocardial infarction [MI] or death), ibuprofen at prescription doses has been associated with a range from no risk (adjusted rate ratio: 0.96 ; $95 \%$ CI: $0.81-1.14)^{33}$ to a significantly increased risk (hazard ratio [HR]: 1.84; $95 \%$ CI: $1.62-2.08 ; P<0.01) .{ }^{34}$ Prescription doses of naproxen have been associated with a significantly decreased risk (adjusted rate ratio: $0.75 ; 95 \%$ CI: $0.62-0.92)^{33}$ to significantly increased risk (adjusted OR: 1.27 ; $95 \%$ CI: 1.01-1.60; $P=0.04$ ) for $\mathrm{CV}$ events when taken within the previous 3 months. ${ }^{35}$

There are few data on actual CV risk with NSAID use at OTC doses, but risk is likely to be small, especially in younger patients who have few CV risk factors. ${ }^{27}$ It has been hypothesized that the increase in CV risk among NSAID users stems from increased blood pressure (BP) due to COX-2 inhibition in the kidneys - an effect that has not been observed with OTC doses. ${ }^{27}$ The PAIN study ( $\mathrm{n}=2,886$ for OTC ibuprofen), although not specifically designed and/or powered to assess $\mathrm{CV}$ risk, reported a low rate ofCV events (0.4\%) with OTC ibuprofen (up to $1,200 \mathrm{mg} / \mathrm{d}$ ) that was not significantly different from that of either aspirin (up to $3,000 \mathrm{mg} / \mathrm{d} ; 0.7 \% ; P=0.13$ ) or acetaminophen (up to $3,000 \mathrm{mg} / \mathrm{d}$; $0.6 \% ; P=0.28$ ). ${ }^{20}$ Although prescription NSAIDs (especially COX-2 inhibitors) are associated with increased risk of death in patients with chronic heart failure, risk does not appear to be increased with OTC ibuprofen (HR: 0.99 for doses $\leq 1,200 \mathrm{mg} / \mathrm{d}$ ) or naproxen (HR: 0.88 for doses $\leq 500 \mathrm{mg} / \mathrm{d}$ ) in these patients. $^{36}$
As noted above, the labeling for OTC NSAIDs indicates a potential increase in stroke risk if taken at higher doses or for longer than recommended durations. ${ }^{29,30}$ A longitudinal cohort study in Denmark reported that risk of stroke is slightly increased (standardized mortality ratio of 1.10 [95\% CI: 1.0-1.3] for hemorrhagic stroke and 1.18 [95\% CI: 1.1-1.3] for other stroke) among users of prescription ibuprofen. ${ }^{37}$ However, a second longitudinal cohort study comparing new users of NSAIDs or COX-2 inhibitors with nonusers in a Pennsylvania Medicare drug benefit program found no increased risk of stroke with ibuprofen (rate ratio: 0.95 ; 95\% CI: $0.78-1.16$ ) or naproxen (rate ratio: 0.83 ; $95 \% \mathrm{CI}$ : $0.67-1.04){ }^{33}$

\section{Renal toxicity}

All NSAIDs can alter renal function by inhibiting COX-1 (which regulates renal hemodynamics and glomerular filtration) and/or COX-2 (which mediates salt and water excretion) expressed in the kidneys. ${ }^{38}$ Uncommon, but concerning, renal syndromes caused by nonselective NSAIDs include sodium retention, peripheral edema, increased BP and weight, congestive heart failure (rare), hyperkalemia, and acute renal failure. ${ }^{38}$ Risk factors include preexisting severe hepatic or renal dysfunction, nephrotic syndrome with high-level proteinuria, older age, diabetes, hypertension, and congestive heart failure. ${ }^{38}$ Furthermore, individuals experiencing renal stress (eg, dehydration) from exercise in hot environments may be at a small increased risk for acute renal failure with ibuprofen. ${ }^{39}$ A nested case-control analysis of new prescription NSAID users over 65 years of age in Quebec, Canada, ( $n=4,228$ cases hospitalized for acute renal failure; $n=84,540$ matched controls) found that risk of renal failure was increased with current new use of NSAIDs (rate ratio: 2.05; 95\% CI: 1.61-2.60), including naproxen (rate ratio: 2.42; 95\% CI: $1.52-3.85$ ), conventional NSAIDs (rate ratio: 2.30; $95 \%$ CI: $1.60-3.32$ ), and celecoxib (rate ratio: 1.54 ; 95\% CI: $1.14-2.09) .^{40}$

NSAIDs may lessen response to diuretics and worsen renal insufficiency associated with use of angiotensinconverting enzyme inhibitors (ACEIs) and angiotensin II receptor blockers (ARBs) ${ }^{38}$ however, a study of OTC analgesics in elderly patients with diuretic-treated hypertension and mild renal insufficiency found no significant impact of ibuprofen on creatinine clearance nor on blood urea nitrogen, serum creatinine, sodium, or potassium levels. ${ }^{41}$

Indeed, OTC ibuprofen in general has been shown to have a low risk of renal AEs. In a case-control study of Tennessee 
Medicaid recipients $(\mathrm{N}=11,698)$, OTC ibuprofen doses were not associated with increased risk for acute renal failure; however, the risk increased dose dependently (adjusted ORs: 0.94, 1.89 , and 2.32 at $\leq 1,200,>1,200-<2,400$, and $\geq 2,400 \mathrm{mg} / \mathrm{d}$, respectively). ${ }^{42}$

Randomized controlled trials (RCTs) have found no increased risk for renal failure in children taking ibuprofen for fever. ${ }^{43,44}$ Despite evidence from large clinical trials, case studies have reported renal failure in children taking OTC ibuprofen; dehydration may have been a contributing factor. ${ }^{45,46}$ There have also been cases reported of transient renal failure among children with cystic fibrosis who were concurrently treated with ibuprofen and intravenous aminoglycosides. ${ }^{47}$

In summary, risk of GI bleeding varies by NSAID and is related to both dose and duration of treatment. Short-term, infrequent use of ibuprofen at OTC doses has a low risk similar to that of acetaminophen and less than that of aspirin. Bleeding risk is increased if NSAIDs are used concomitantly with aspirin and decreased if used with ulcer-healing drugs. All non-aspirin NSAIDs may increase CV thrombotic risk, based largely on epidemiological studies of prescription NSAID use. Limited data are available to allow for assessment of the magnitude of this risk in users of OTC NSAIDs, but risk is likely to be low, especially in young patients with few CV risk factors. Long-term use of high-dose NSAIDs may increase stroke risk, but the corollary among short-term users of low-dose NSAIDs is not well defined. Renal toxicity is an uncommon AE of all NSAIDs, and risk is elevated in those who have preexisting severe hepatic or renal dysfunction, nephrotic syndrome with high-level proteinuria, older age, diabetes, hypertension, congestive heart failure, or dehydration. NSAIDs may lessen response to diuretics and worsen renal insufficiency associated with use of ACEIs and ARBs. Risk of these interactions and renal AEs is low among users of OTC ibuprofen.

\section{Overdose}

Unlike acetaminophen and aspirin, the margin of safety (ie, difference between minimal effective dose and minimal toxic dose) with ibuprofen is high, and ibuprofen is not associated with a substantial incidence of serious ADRs in cases of overdose. ${ }^{48}$ A comparative study found that among 10,134 reported cases of overdose with acetaminophen (48.0\%), aspirin (36.6\%), and ibuprofen (15.4\%) reported to US poison control centers, life-threatening or fatal events were reported in $5.6 \%, 5.9 \%$, and $1.6 \%$ of adults and in $0.3 \%, 0.4 \%$, and $0.4 \%$ of children, respectively. ${ }^{49}$

\section{Potential drug interactions Antihypertensives}

Hypertension and chronic pain can be frequent comorbidities in the elderly and those with chronic disease; therefore, concomitant use of NSAIDs and antihypertensives is common. ${ }^{50}$ Efficacy of medications that act on renal prostaglandins (eg, furosemide) or modify their effects (eg, other diuretics or ACEIs) may be reduced, resulting in increases in BP with NSAID coadministration because of inhibition of renal prostaglandins and increased fluid retention. ${ }^{38}$

Some trials found increased risk of DDIs when prescriptionstrength NSAIDs and antihypertensives were coadministered over a period of multiple weeks. ${ }^{50,51}$ Other trials found no significant effect on BP when OTC doses of ibuprofen or naproxen ${ }^{52}$ or prescription-dose ibuprofen ${ }^{53,54}$ were combined with antihypertensives. A recent post hoc analysis of an RCT comparing the effects of lumiracoxib (a prescription COX-2 inhibitor; $100 \mathrm{mg} / \mathrm{d})$ with prescription ibuprofen $(1,800 \mathrm{mg} / \mathrm{d})$ in OA patients with hypertension controlled on stable doses of antihypertensive medication(s) observed small but consistent increases of $2.2 \mathrm{mmHg}$ overall versus baseline in 24-hour mean systolic BP (SBP) in the ibuprofen-treated group. The greatest increases occurred when ibuprofen was combined with ARBs or ACEIs (Figure 2). ${ }^{55}$

In addition to effects on BP, there is concern that an interaction between NSAIDs and antihypertensive agents may increase the risk of acute kidney injury, since each of these classes of drugs affects kidney function via differing

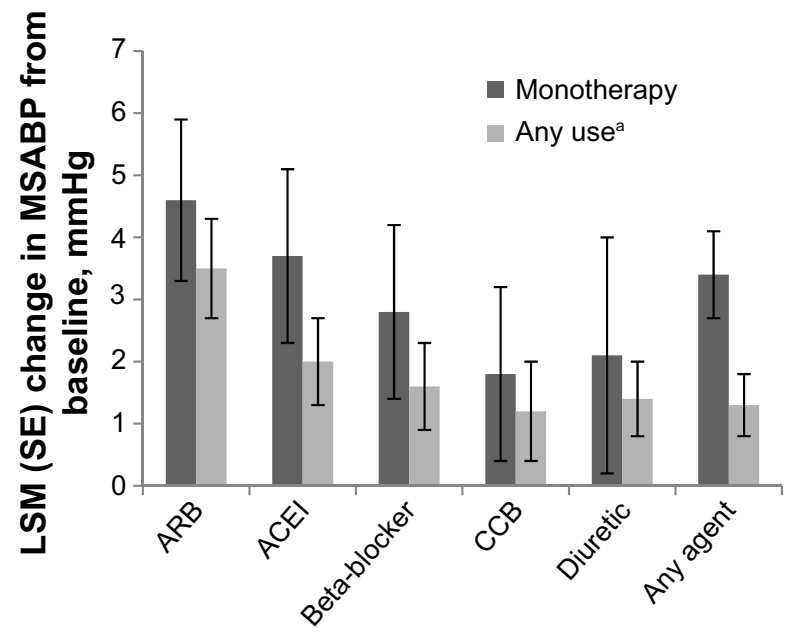

Figure 2 Summary of changes in systolic ambulatory blood pressure when prescription ibuprofen $(1,800 \mathrm{mg} / \mathrm{d})$ and antihypertensives are coadministered.

Notes: any use $=$ monotherapy or free- and fixed-dose combinations. For the final "any agent" category, the "any use" data represent free- or fixed-dose combinations only. Data from MacDonald et al. ${ }^{55}$

Abbreviations: ACEI, angiotensin-converting enzyme inhibitor; $A R B$, angiotensin II receptor blocker; CCB, calcium channel blocker; LSM, least squares mean; MSABP, mean systolic ambulatory blood pressure; SE, standard error. 
mechanisms.$^{56}$ A large case-control analysis consisting of 2,215 cases of acute kidney injury and 21,993 controls without kidney injury, all of whom were taking antihypertensive agents, found that risk of acute kidney injury was not significantly increased when NSAIDs were combined with diuretics, ACEIs, or ARBs; however, a significant increase was observed in those taking triple therapy consisting of an NSAID, a diuretic, and either an ACEI or an ARB (adjusted rate ratio: $1.31 ; 95 \%$ CI: $1.12-1.53) .{ }^{56}$ In another study, four of 17 African American women who received fosinopril $10-40 \mathrm{mg} / \mathrm{d}$ and hydrochlorothiazide (HCTZ) $25 \mathrm{mg} / \mathrm{d}$ for hypertension and ibuprofen $2,400 \mathrm{mg} / \mathrm{d}$ over 1 month for OA developed acute renal failure (ie, glomerular filtration rate decrease $\geq 25 \%$ ). ${ }^{54}$

\section{Renin-angiotensin-aldosterone system inhibitors}

Inhibitors of the renin-angiotensin-aldosterone system include antihypertensives such as ACEIs, ARBs, and direct renin inhibitors. A 4-week RCT of prescription ibuprofen $(2,400 \mathrm{mg} / \mathrm{d})$, nabumetone $(2,000 \mathrm{mg} / \mathrm{d})$, celecoxib $(400 \mathrm{mg} / \mathrm{d})$, or placebo in hypertensive patients $(\mathrm{N}=385)$ receiving an ACEI found that ibuprofen coadministration, but not nabumetone or celecoxib coadministration, significantly increased SBP by a mean \pm standard error of $6.5 \pm 1.4$ $\mathrm{mmHg}(P=0.0001)$ and diastolic BP by $3.5 \pm 0.9 \mathrm{mmHg}$ $(P=0.0069)$ from baseline..$^{50}$ Prescription-strength ibuprofen was also associated with the greatest percentage of patients who experienced SBP changes of clinical concern, defined as a $20 \mathrm{mmHg}$ increase from baseline and measuring $>140 \mathrm{mmHg}$ : $16.7 \%$ versus $5.5 \%$ in the nabumetone group, $4.6 \%$ in the celecoxib group, and $1.1 \%$ in the placebo group $(P<0.001$ for ibuprofen vs placebo). ${ }^{50} \mathrm{~A}$ Croatian prospective trial $(\mathrm{N}=110)$ evaluated the effects of prescription NSAIDs (piroxicam or ibuprofen; $\mathrm{n}=60$ ) taken for OA on antihypertensive activity of a calcium channel blocker (amlodipine) or an ACEI/thiazide diuretic (lisinopril/HCTZ) combination. Compared with baseline, mean arterial pressure increased by $9.5 \mathrm{mmHg}(8.9 \%)$ with ibuprofen and by $10.2 \mathrm{mmHg}(9.5 \%)$ with piroxicam (both $P<0.001)$ in patients taking lisinopril/ HCTZ; there was a nonsignificant $0.5 \mathrm{mmHg}(0.5 \%)$ increase in mean arterial BP with either NSAID among patients taking amlodipine..$^{57}$

Few data on potential DDIs between direct renin inhibitors and NSAIDs have been reported; however, a single report from three open-label studies of aliskiren found that concurrent administration with celecoxib $(n=22)$ resulted in minor changes to the pharmacokinetic profile of aliskiren but not that of celecoxib. ${ }^{58}$
It should also be noted that aldosterone antagonists (eg, spironolactone) are associated with an increased risk of GI bleeding and possibly impaired healing of gastric or duodenal erosions. ${ }^{59}$ Thus, risk of GI bleeding in patients taking these agents may be further increased when NSAIDs are used concomitantly. ${ }^{60}$ Patients treated long term with aldosterone antagonists should be informed of the risk of upper GI bleeding and perhaps warned of the risk of using OTC NSAIDs long term.

\section{Diuretics}

Thiazide diuretics (eg, HCTZ) are also associated with potential DDIs when combined with NSAIDs. ${ }^{61}$ A randomized, double-blind, two-period crossover trial evaluating the effects of 4 weeks of prescription ibuprofen $(1,800 \mathrm{mg} / \mathrm{d})$ or placebo (4 weeks' treatment; 2-week washout period between treatments) in combination with HCTZ in hypertensive patients $(\mathrm{N}=25)$ found that ibuprofen significantly increased SBP by $4.2 \mathrm{mmHg}$ (supine) and $4.7 \mathrm{mmHg}$ (standing) compared with placebo $(P \leq 0.004) .{ }^{51}$ An RCT examining the effect of prescription ibuprofen $(2,400 \mathrm{mg} / \mathrm{d})$ and naproxen $(750 \mathrm{mg} / \mathrm{d})$ on $\mathrm{BP}$ in patients $(\mathrm{N}=97)$ with mild essential hypertension treated with HCTZ $50 \mathrm{mg} / \mathrm{d}$ found a $<3 \mathrm{mmHg}$ mean increase in diastolic BP from baseline during the 4-week study for either treatment group, the clinical effects of which were likely minor. ${ }^{62}$ A single-blind, factorial, parallel-group study $(\mathrm{N}=88)$ found that patients taking lisinopril/HCTZ $(n=29)$ who were randomly assigned to concurrent prescription ibuprofen $(1,200-1,800 \mathrm{mg} / \mathrm{d})$ or piroxicam $(10-20 \mathrm{mg} / \mathrm{d})$ experienced SBP elevations of up to $7.7 \%(P=0.004)$ and $9.5 \%(P=0.001)$, respectively, compared with baseline. ${ }^{63}$ An open-label, randomized, five-way crossover study comparing placebo, furosemide alone, furosemide with oral diclofenac, furosemide with diclofenac epolamine patch, or furosemide with ibuprofen $2,400 \mathrm{mg} / \mathrm{d}(\mathrm{N}=40)$ found that although prescription ibuprofen administration decreased clearance of furosemide and increased urine sodium excretion, no clinically relevant effect on BP was observed in healthy volunteers. ${ }^{64}$ Topical diclofenac had no effect on furosemide pharmacokinetics or pharmacodynamics, and oral diclofenac compared with furosemide alone decreased urine output, but neither formulation was associated with alterations in BP. ${ }^{64}$

\section{$\beta$-adrenergic and calcium channel blockers}

Some NSAIDs, including indomethacin and flurbiprofen (but not naproxen or aspirin), have been found to interact with $\beta$-blockers (eg, propranolol, oxprenolol, atenolol), 
attenuating their antihypertensive effects. ${ }^{65}$ In an RCT of prescription-strength ibuprofen $(1,600 \mathrm{mg} / \mathrm{d})$ plus propranolol, no significant increase in BP was found. ${ }^{66}$ As noted earlier, a post hoc analysis of an RCT demonstrated that prescription ibuprofen $(1,800 \mathrm{mg} / \mathrm{d})$ produced a small increase in SBP when combined with $\beta$-blocker $(2.8 \mathrm{mmHg})$ or calcium channel blocker $(1.8 \mathrm{mmHg}) .{ }^{55}$ Calcium channel blockers such as verapamil and amlodipine do not appear to be associated with clinically significant interactions with NSAIDs. ${ }^{52,57}$ These results are expected from the mechanisms of action of both drug families. ${ }^{52}$

In summary, these data suggest that prescription-strength NSAIDs, including ibuprofen, may be associated with small but statistically significant increases in BP that are greatest when coadministered with ARBs and ACEIs and lowest with calcium channel blockers and loop diuretics. The clinical relevance of these findings remains unclear, although one analysis that modeled the effects of hypertension in patients taking COX-2 inhibitors predicted that NSAID-driven hypertension may contribute to $\mathrm{CV}$ events and deaths. ${ }^{67}$ Given the clear dose- and duration-response relationship between ibuprofen use and ADRs in general ${ }^{43}$ and the very small increase in BP observed with prescription-strength NSAIDs, any DDI occurring with short-term OTC ibuprofen and antihypertensives would most likely have only a minor effect on BP. However, of most concern is potential inhibition of antihypertensive efficacy with chronic use of higher doses. Thus, hypertensive patients who require ARBs, ACEIs, or thiazide diuretics such as HCTZ should avoid chronic prescription NSAID use.

\section{Antithrombotics}

Interactions between NSAIDs and several classes of antithrombotic drugs, including aspirin and warfarin, have been reported. This section will discuss DDIs resulting in CV changes as well as DDIs with aspirin and other NSAIDs that may contribute to asthma exacerbations (by a nonallergic mechanism).

\section{Aspirin}

Coadministration of aspirin and most NSAIDs (other than diclofenac and ketorolac) can lead to pharmacodynamic DDIs resulting from competition for access to the acetylation site of platelet-expressed COX-1. ${ }^{68-70}$ NSAID-driven reversible, transient inhibition of platelet aggregation blocks aspirin's irreversible inhibition, thereby potentially allowing clot formation. ${ }^{68}$ This NSAID-driven effect on aspirin is of particular concern in individuals at high $\mathrm{CV}$ risk who take low-dose aspirin daily to reduce the risk of a thrombotic event. ${ }^{68,69}$ A case-control study $(\mathrm{N}=5,208$, including 1,055 cases of first nonfatal MI and 4,153 community controls) found that patients taking daily prophylactic aspirin plus ibuprofen four or more times/week (doses not reported) had double the risk of an MI compared with aspirin-only users, although the difference was not statistically significant (OR: 2.03; 95\% CI: 0.60-6.84), whereas the OR for MI with infrequent use (less than four times/week) of ibuprofen plus daily aspirin was 0.60 (95\% CI: $0.21-1.66) .{ }^{71}$ Other studies also indicate that concomitant aspirin and ibuprofen could increase the possibility of experiencing a $\mathrm{CV}$ event, ${ }^{72,73}$ but one of these found no increase in risk of MI associated with intermittent use of NSAIDs ( $<60$ days/year) in healthy persons without $\mathrm{CV}$ disease. ${ }^{72}$

These data and interpretation of risk are somewhat confounded by other studies suggesting that risk for a $\mathrm{CV}$ event may actually be reduced with concomitant aspirin and ibuprofen. In a single-center, retrospective analysis, patients prescribed aspirin (typically $325 \mathrm{mg} / \mathrm{d}$ ) and ibuprofen (mean $1,947 \mathrm{mg} / \mathrm{d})(\mathrm{n}=3,859)$ experienced $\sim 40 \%$ fewer MIs than those prescribed aspirin alone $(\mathrm{n}=10,239$; rate ratio: 0.61 ; 95\% CI: $0.50-0.73 ; P<0.001) .{ }^{74}$ A retrospective study $(\mathrm{N}=42,611$, including 8,688 cases with $\mathrm{MI}$ and 33,923 controls) found that patients prescribed aspirin and any NSAID (doses not assessed for either treatment) had a lower risk for MI than those who did not take aspirin and/or NSAIDs (OR: 0.74; 95\% CI: 0.57-0.97). In addition, individuals taking ibuprofen plus aspirin in this study had a lower OR for MI (OR: 0.69; 95\% CI: 0.42-1.15) than did those taking aspirin with an NSAID other than ibuprofen (OR: 0.76; 95\% CI: 0.56-1.04)..$^{75}$

There have been case reports in which ibuprofen may have precipitated an asthma exacerbation in adults and children with aspirin-sensitive asthma, ${ }^{76-79}$ possibly as a result of increased leukotriene synthesis in response to COX inhibition and related depletion of protective prostaglandins. ${ }^{78,80}$ The risk of ibuprofen-sensitive asthma was low $(\sim 2 \%)$ in a small RCT $(\mathrm{N}=100)$ of children with asthma and no known aspirin or ibuprofen sensitivity, suggesting that the prevalence of ibuprofen-sensitive asthma in the general population of asthmatics is also low. ${ }^{81}$ In a large RCT in asthmatic children with febrile illness and no known sensitivity or bronchospastic reactivity to aspirin or other NSAIDs $(\mathrm{N}=1,879)$, Lesko et al found no more hospital admissions (RR: 0.63; 95\% CI: 0.25-1.6) and actually fewer outpatient consultations for asthma symptoms or exacerbation. ${ }^{43}$ 


\section{Warfarin}

As a class, NSAIDs are not prone to a direct pharmacodynamic interaction with anticoagulants such as warfarin; however, concurrent use of NSAIDs and antithrombotics may further increase the likelihood of GI bleeding. ${ }^{82}$ A Danish cohort study $(\mathrm{N}=4,204)$ found that anticoagulants alone increased the risk of GI bleeding (standardized incidence ratio [SIR]: 4.0; 95\% CI: 2.8-5.6), and risk was further increased by concomitant use of acetaminophen (SIR: 4.4 ; $95 \%$ CI: $1.2-$ 11.4) or non-aspirin NSAIDs (SIR: 8.0; 95\% CI: 2.1-20.4; no specific NSAIDs or doses reported) ${ }^{83}$ Metabolism of S-warfarin, the most clinically relevant warfarin isomer, ${ }^{84}$ occurs via CYP2C9. ${ }^{85}$ Ibuprofen and other NSAIDs are also substrates of CYP2C9 ${ }^{85}$ and may thus increase anticoagulant activity by delaying S-warfarin metabolism. ${ }^{86}$ Therefore, it may be prudent to avoid prescription-strength NSAIDs in patients receiving warfarin. In contrast, one of the metabolites of acetaminophen ( $\mathrm{N}$-acetyl-para-benzoquinone-imine) interferes with enzymes involved in the vitamin $\mathrm{K}$ cycle, which ultimately can lead to reduction in synthesis of clotting factors and excessive anticoagulation. ${ }^{87}$ Even with short-term use, acetaminophen given concurrently with anticoagulants may increase international normalized ratio (INR), implying an increase in bleeding risk and necessitating close INR monitoring and possible warfarin dosage adjustments. ${ }^{88-91}$

In conclusion, although the clinical effect of DDIs between NSAIDs and aspirin is unclear, clinicians may wish to counsel patients taking a daily aspirin to avoid chronic use of ibuprofen, which may reduce aspirin's ability to prevent CV events. ${ }^{92}$ The FDA recommends taking ibuprofen $\geq 8$ hours before or $\geq 30$ minutes after immediate-release (not entericcoated) of aspirin to reduce the likelihood of a potential interaction on platelet function. ${ }^{93}$ In addition, ibuprofen should be avoided in patients with known or suspected aspirin-sensitive asthma. Patients should be counseled to limit their use of OTC NSAIDs and to avoid acetaminophen while on anticoagulant therapy, the former because of the increased risk of GI bleeding with NSAIDs, however small, and the latter because of the direct interaction that would increase the risk of all-site bleeding.

\section{Antidepressants/mood stabilizers}

Antidepressants are psychiatric medications used to alleviate mood and anxiety disorders. Some antidepressants may be associated with an increased risk for bleeding, which may be additively enhanced by coadministration of NSAIDs.

\section{Selective serotonin reuptake inhibitors and tricyclic} antidepressants

Selective serotonin reuptake inhibitors (SSRIs) increase bleeding risk by inhibiting platelet adhesion and function. ${ }^{94-96}$ Coadministration of NSAIDs in patients taking SSRIs can substantially increase the risk of bleeding. ${ }^{97,98}$ A Dutch population-based cohort study $(\mathrm{N}=1,961)$ found that patients prescribed SSRIs plus NSAIDs were prescribed ten times more peptic ulcer drugs (proxy for GI events) than patients receiving an SSRI alone (incidence rate ratios: 12.4; 95\% CI: $3.2-48.0$ vs $1.2 ; 95 \%$ CI: $0.5-2.8$, respectively).$^{98}$ In a case-control study utilizing a UK general practice research database to identify cases of upper GI bleeding $(n=1,651)$ or ulcer perforation $(n=248)$ and age/sex/time-matched controls $(n=10,000)$, concurrent use of NSAIDs and SSRIs had a more than multiplicative effect on risk of bleeding. Compared with nonuse of both drug classes, RR $(95 \% \mathrm{CI})$ for bleeding was 2.6 (1.7-3.8) with SSRIs, 3.7 (3.2-4.4) with NSAIDs, and $15.6(6.6-36.6)$ with concurrent use of both. ${ }^{97}$ NSAID dosages and durations were not evaluated individually in these studies.

Several mechanisms may account for the interaction between SSRIs and NSAIDs: 1) both classes inhibit platelet aggregation and function but via different mechanisms; ${ }^{94,99}$ 2) a pharmacokinetic interaction in which some SSRIs inhibit CYP2C9, an enzyme responsible for the metabolism of some NSAIDs (eg, ibuprofen and diclofenac); ${ }^{100}$ or 3) independent effects in which SSRIs increase symptoms and bleeding via an independent mechanism without any direct pharmacokinetic interaction (eg, by increasing gastric acid secretion). ${ }^{101}$ Tricyclic antidepressants (TCAs) do not substantially inhibit CYP2C9. ${ }^{100}$ In the Dutch cohort study, in contrast to the tenfold increase in risk when NSAIDs are added to SSRIs, patients receiving TCAs plus an NSAID experienced a more modest increase in GI events (incidence rate ratio: 2.5 ; 95\% CI: $0.3-20.3$ ) compared with those receiving TCAs alone. ${ }^{98}$

\section{Lithium}

Several prescription-strength NSAIDs have been associated with substantial DDIs resulting in ADRs when coadministered with lithium. One study assessed reports of DDIs between lithium and selective COX-2 inhibitors as reported in the FDA's Adverse Event Reporting System database as of January 2003. ${ }^{102}$ Thirteen cases of increased lithium concentration were reported with rofecoxib (plasma concentration increased by $58 \%-448 \%$ ), and five were reported with celecoxib (plasma concentration increased by 
56\%-99\%). Increased lithium concentrations were associated with clinical AEs including tremor, nausea/vomiting, upset stomach, renal insufficiency, weakness, ataxia, increased muscle tone, dysarthria, slurred speech, lethargy, sedation, disorientation, nystagmus, and flu-like symptoms. ${ }^{102}$ The DDI mechanism is unclear; however, NSAID-mediated inhibition of renal prostaglandins may decrease renal lithium excretion. ${ }^{103}$ In two small studies, prescription ibuprofen $(1,800 \mathrm{mg} / \mathrm{d}$ in nine patients) and naproxen $(750 \mathrm{mg} / \mathrm{d}$ in six patients) increased lithium levels. ${ }^{104,105}$

In summary, although it is clear that prescription-strength NSAIDs should not be routinely taken with SSRIs, it is unclear whether there is sufficient increase in risk with OTC NSAIDs to warrant avoiding their occasional use with SSRIs. Evidence is currently lacking to determine whether ibuprofen or other nonselective NSAIDs administered at OTC doses and durations increase the likelihood of a DDI with lithium. Caution may be advised for older patients and those with altered renal function for whom individual dose adjustments may be necessary.

\section{Alcohol}

Alcohol intake is an independent risk factor for GI bleeding that is exacerbated in a dose-dependent manner in individuals taking NSAIDs. These additive effects may be related to a direct toxicity on the gastric mucosa, the development of esophageal varices, and decreased synthesis of coagulation factors in chronic alcoholic liver disease and cirrhosis. Kaufman et al conducted an interview-based case-control survey $(\mathrm{N}=4,169)$ of 1,224 inpatients in the US and Sweden with GI bleeding and 2,945 matched neighborhood controls. They found a 2.7-fold higher risk for GI bleeding in individuals who regularly took ibuprofen (at least every other day) at any dose in the week prior to the onset of hematemesis/melena and who drank any amount of alcohol (95\% CI: 1.6-4.4). Occasional ibuprofen use was not associated with an increased risk of acute GI bleeding (multivariate RR estimate: 1.2 ; 95\% CI: $0.8-1.7) .{ }^{106}$ Risk for ADRs in individuals who consume three or more alcoholic drinks every day is also high with non-NSAID analgesics such as aspirin (GI bleeding) and acetaminophen (hepatic dysfunction or failure). ${ }^{107}$

\section{Herbal/nutraceutical ingredients}

Herbal/nutraceutical ingredients are a potential concern primarily because patients do not routinely discuss their use with health care providers, while, in some instances, they may carry a risk of DDIs similar to pharmaceutical products.

\section{St John's wort}

St John's wort, Hypericum perforatum, is an herbal supplement commonly used for treatment of depression. Its active ingredient, hyperforin, inhibits uptake of serotonin, norepinephrine, and dopamine. ${ }^{108}$ St John's wort is a known inducer of multiple CYP enzymes, including CYP3A4, CYP2E1, and CYP2C19, and, as such, it has considerable potential for DDIs; ${ }^{109}$ however, it does not affect CYP2C $9,{ }^{109}$ an enzyme that metabolizes some NSAIDs. ${ }^{100}$ A small study in healthy male volunteers $(\mathrm{N}=8)$ found no effect of coadministration of St John's wort and ibuprofen on either maximum concentration or area under the plasma concentration-time curve of ibuprofen but did identify a significant $31 \%$ decrease in S-ibuprofen residence time $(P=0.02) .{ }^{110}$ No other reports describe a clinically relevant effect of St John's wort on ibuprofen kinetics; therefore, occasional coadministration of OTC ibuprofen with St John's wort should not be problematic apart from a possible interaction with platelet activity similar to that observed with SSRIs.

\section{Ginkgo biloba}

Ginkgo is an herbal therapy taken to improve memory and concentration, reduce tinnitus, and potentially treat peripheral vascular disease. The putative effects of NSAID-Ginkgo interaction are primarily anecdotal; ${ }^{111,112}$ for example, one case was reported of fatal intracerebral mass bleeding in a 71-year-old man taking Ginkgo and ibuprofen. ${ }^{112}$ A systematic review of eight RCTs concluded that ginkgo, in and of itself, does not appear to cause clinically important changes in blood coagulation. ${ }^{113}$ Although some researchers warn against coadministration of ibuprofen with Ginkgo, ${ }^{114}$ others find there is insufficient evidence to support a serious health risk from combining Ginkgo and NSAIDs. ${ }^{111}$

\section{Antirheumatics/chemotherapy Methotrexate and probenecid}

Methotrexate is an antimetabolite used at high doses as a chemotherapeutic and at low doses for treatment of psoriasis and RA. ${ }^{115}$ Several NSAIDs, including prescription ibuprofen and naproxen, have been found to reduce renal clearance of methotrexate, ${ }^{10,116,117}$ which could lead to toxicity (eg, renal failure or pancytopenia), at least when methotrexate is used at high doses. ${ }^{10} \mathrm{~A}$ single-case report speculated that daily use of an OTC ibuprofen product for 4 weeks reduced methotrexate excretion. Resulting methotrexate accumulation caused bone marrow depletion, which may have contributed to Pneumocystis carinii pneumonia in a patient with Crohn's disease. ${ }^{118}$ Given that renal effects have also 
been reported with prescription ibuprofen monotherapy, ${ }^{119}$ patients taking high-dose methotrexate should avoid NSAID use, even at OTC doses. Additionally, caution should be exercised when NSAIDs are used in patients receiving lowdose methotrexate. ${ }^{115}$ No other reports of clinically relevant DDIs resulting in ADRs in individuals receiving concomitant NSAIDs and chemotherapeutics or rheumatologic therapies were identified.

In a study of eight healthy volunteers, aspirin antagonized the uricosuric effect of probenecid, a treatment for gout; however, ibuprofen administration had no effect on probenecid activity. ${ }^{120}$

\section{Female health effects}

Reports in the literature have suggested that NSAIDs may reduce the (now-contested) cardioprotective effect of hormone replacement therapy (HRT) and may be associated with increased risk for miscarriage.

\section{HRT}

The hypothetical interaction of NSAIDs and HRT was proposed based on results from a case-control study of women aged $50-84$ years $(\mathrm{N}=8,678)$ who had $(\mathrm{n}=1,673)$ or had not ( $\mathrm{n}=7,005)$ experienced an MI. ${ }^{121}$ Women currently taking HRT (but no NSAIDs) had a reduced risk of MI (OR: 0.64; 95\% CI: 0.48-0.85), whereas there was a trend toward increased risk of MI among women who took both HRT and NSAIDs (any dose; OR: 1.71; 95\% CI: 1.05-2.78). The authors concluded that there was a putative cardioprotective effect of HRT alone that may be undermined by NSAIDs. ${ }^{121}$ However, the benefit of HRT on long-term CV health in postmenopausal women has largely been disproven by the Women's Health Initiative study. ${ }^{122-124}$ Interestingly, a recent randomized study $(\mathrm{N}=1,006)$ reexamining the effect of HRT on perimenopausal or recently postmenopausal women aged 45-58 years found that HRT significantly reduced CV events; ${ }^{125}$ however, no association with NSAIDs was examined.

\section{Fertility effects}

The hypothesis that NSAIDs may interfere with conception was proposed to explain why some women with RA treated with long-term diclofenac were unable to conceive until after stopping diclofenac. ${ }^{126}$ A Danish case-control study that included 4,268 women who had miscarried and 29,750 controls who had had live births reported an increased risk for miscarriage associated with prescription NSAID use, especially soon after NSAIDs were taken. ${ }^{127}$ When study data were reassessed with a consideration for gestational age, this association was diminished in strength, but still positive. ${ }^{128}$ The authors acknowledged that they could not rule out the possibility that NSAIDs may have been taken to relieve pain caused by the impending miscarriage ${ }^{127,128}$ (ie, a protopathic bias ${ }^{129}$ ). A population-based cohort study of pregnant women in the Kaiser Permanente Medical Care Program in San Francisco, CA, USA (N=1,055), found that NSAIDs (doses not reported) were associated with an $80 \%$ increased risk for miscarriage (HR: $1.8 ; 95 \%$ CI: 1.0-3.2), with even higher risks when NSAIDs were taken close to the time of conception or for longer than 1 week. ${ }^{130}$ There was a trend toward increased risk with aspirin use (HR: 1.6; 95\% CI: 0.6-4.1) but no increase in risk associated with acetaminophen (HR: 1.2; 95\% CI: 0.8-1.8).

While data are limited, it has been hypothesized that NSAID use may reduce fertility and increase the risk of miscarriage. It may be prudent for women who are trying to become pregnant to avoid NSAID use around the time of conception. ${ }^{130}$ Additionally, prostaglandins play an important role in maintaining the patency of the fetal ductus arteriosus during the third trimester of pregnancy. ${ }^{131}$ As a result, OTC ibuprofen product labeling advises consumers that:

It is especially important not to use ibuprofen during the last 3 months of pregnancy unless definitely directed to do so by a doctor because it may cause problems in the unborn child or complications during delivery. ${ }^{29}$

\section{Corticosteroids}

Combined use of oral corticosteroids and NSAIDs may increase the potential for serious GI toxicity. A study of Tennessee Medicaid beneficiaries, including 1,415 patients $\geq 65$ years of age hospitalized for peptic ulcer or upper GI bleeding and 7,063 matched controls, found that current use of oral corticosteroids was associated with a twofold higher RR of peptic ulcer disease compared with nonuse. ${ }^{132}$ On further analysis, this increased risk was attributed to a 4.4-fold increased risk for peptic ulcer disease in individuals who had also taken NSAIDs (any type or dosage) compared with no elevated risk when NSAID users were excluded (RR: 1.1). ${ }^{132}$ As discussed above, the Arthritis, Rheumatism, and Aging Medical Information System study found that for patients who received corticosteroids plus other concurrent therapy, the risk of serious GI events was significantly greater with acetaminophen versus ibuprofen (any dose) in patients with RA (15.0 vs 6.1 events/1,000 patient-years, respectively) or OA (12.0 vs 5.4 events/1,000 patient-years, respectively) across all comparable doses. ${ }^{22}$ 
A limited nonclinical study suggests that an ulcerogenic potential of NSAIDs in combination with corticosteroids was seen only with a COX-1, but not a COX-2, inhibitor. ${ }^{133}$ This effect may occur as a result of corticosteroid-induced reductions in arachidonic acid, reducing the substrate for COX enzymes and thus potentially increasing the gastrotoxic effect of NSAIDs.

In summary, although no specific studies have identified a clear risk for increased GI bleeding when OTC NSAIDs are coadministered with oral corticosteroids, it may be prudent for health care providers to prescribe COX-2-specific NSAIDs or counsel patients to avoid OTC NSAIDs to reduce the potential risk for GI bleeding.

\section{Discussion}

Prescription-strength ibuprofen and other NSAIDs are associated with an increased risk for GI bleeding that can be exacerbated when combined with alcohol, SSRIs, corticosteroids, and of course anticoagulants. Increased CV risk seen with some COX-2-specific inhibitors has not been observed to the same degree with prescription ibuprofen; therefore, any potential $\mathrm{CV}$ risk from OTC doses is likely very low. Likewise, the potential risk for renal effects with OTC ibuprofen or other NSAIDs is low. Unlike acetaminophen and aspirin, ibuprofen has a high margin of safety and is not associated with a substantial incidence of serious ADRs in cases of overdose. ${ }^{48}$

Reports of ADRs resulting from DDIs between NSAIDs and various drug classes should be assessed based on a continuum of risk and consideration given to both dose and duration. DDIs reported with ibuprofen are pharmacologically driven and related to inhibition of COX enzymes. Because pharmacologic reactions are dose and duration dependent, safety data from clinical studies of prescription-strength ibuprofen or other NSAIDs used long term (as in the treatment of OA or RA) may not be directly applicable to ibuprofen for OTC dosing and duration of use.

Consideration of the continuum of risk based on dose and duration of NSAID use is especially important for patients taking several concomitant medications. Risk of ADRs correlates with number of concurrent prescriptions. ${ }^{134} \mathrm{~A}$ study of Utah Medicaid recipients ( $\mathrm{N}=391,890)$ revealed that $62 \%$ received one or more medications and $4.3 \%$ received more than seven medications in 1 month. The study authors found an $80 \%$ rate of drug-related problems among those prescribed more than seven medications; treatments for pain or inflammation were implicated in $29.1 \%$ of these problems. ${ }^{135}$ Another study found that elderly, largely mobility-restricted
German patients receiving home general practitioner visits $(\mathrm{N}=779)$ took, on average, 6.8 medications on a regular basis and that $\sim 80 \%$ experienced a DDI, of which $\sim 44 \%$ were considered moderately or seriously relevant. The combination of NSAIDs with thiazide or loop diuretics was the most frequently implicated in moderately relevant DDIs, accounting for $8.5 \%$ of such reactions. ${ }^{61}$

This review was written to educate clinicians on potential DDI risks when OTC NSAIDs are coadministered with common medications. In many instances, studies in the medical literature report only on DDIs occurring with prescription NSAIDs and do not assess risk at OTC doses and durations. Likewise, many of the studies summarized herein are retrospective case-control studies that do not report on specific dosages or durations of use for the NSAIDs discussed. In those cases, the authors have attempted to evaluate whether these risks are clinically relevant at OTC doses and durations. In these DDIs, the concern is not so much that there might be an increase in the very low risk of ADRs associated with the OTC-dose NSAIDs, but that there could be an increase in the risk associated with very active or potentially dangerous drugs, such as oral anticoagulants or cytostatics. In most or all cases, the drugs potentially involved in a DDI are prescription drugs that are known to have a wide range of ADRs and potentially narrow therapeutic ranges. Because all of these drugs are prescribed, patients will see a health care provider upon the occasion of the prescription. It is the health care provider's responsibility to inform the patient about the potential risks associated with the concurrent use of OTC NSAIDs for pain or pyrexia and to warn them against prolonged use or use at higher than recommended OTC doses.

\section{Conclusion}

NSAIDs such as ibuprofen are generally safe and effective for individuals seeking an OTC analgesic/antipyretic. Reports of ADRs arising from DDIs with NSAIDs and common medications occurred primarily in studies of prescription-strength NSAIDs. The pharmacologic basis of these interactions strongly suggests that low-dose, shortterm use of OTC NSAIDs such as ibuprofen should be safe for relief of occasional pain and fever, especially in young, healthy individuals. More caution is warranted in elderly patients with OA or RA, especially those already treated with prescription doses of NSAIDs and those taking an ACEI or diuretic (including spironolactone for heart failure) or lowdose aspirin for prevention of CV events; it may be prudent to advise such patients to avoid use of even short-term OTC NSAIDs unless they are under close medical supervision. 
Health care providers can be instrumental in educating all patients that using the lowest effective dose of OTC NSAIDs for the shortest required duration is vital to balancing efficacy and safety.

\section{Acknowledgments}

Editorial/medical writing support was provided by John O'Flaherty, PhD, of ProEd Communications, Inc., and Lauren Cerruto and John H Simmons, MD, of Peloton Advantage, LLC, and was funded by Pfizer Inc.

\section{Disclosure}

Nicholas Moore is an employee of Bordeaux University and Bordeaux University Hospital. The department he heads has worked or is working with, or has received funds from, Abbott Laboratories, ADDS, AFRETH, Aptalis, Arkopharma, Asahi, AstraZeneca, Aventis, Axcan, Baxter, Bayer, Berkem, Bial, Bioalliance, Biopharma, BMS, BNIA, Boehringer Ingelheim, Boots, Caviar de France, Chaine Thermale du Soleil, Celgene, Cephalon, Daiichi Sankyo, Eli Lilly and Company, Ethicon, Eugénie-lesBains, Expanscience, Génévrier, Genopharm, GlaxoSmithKline, Grunenthal, Guerbet, Helsinn, Horus Pharma, I3, Innothera, Ipsen, Janssen-Cilag, Johnson \& Johnson, Leo Pharma, Lundbeck, Meda Pharmaceuticals, Medtronic, Merck \& Co, Merck Serono, Norgine, Novartis, Novartis Family Health, Novo Nordisk, Nycomed, Orion Corporation, Pfizer, Pfizer FHC, Pierre Fabre, Procter and Gamble, Reckitt Benckiser, Roche, Sanofi, Schering-Plough, Servier, Stallergènes, Takeda, Teva, UCB, Vivalis, Vivatec, Warner Chilcott, Wyeth, and Xanodyne Pharmaceuticals. In addition, public funding for specific projects has been received from the Seventh Framework Program (FP7 [EU]), European Medicines Agency, French Agency for the Safety of Health Products (AFSSAPS), National Agency for the Safety of Medicines and Health Products (MSNA), Directorate General of the Supply of Care (DGOS), French National Authority for Health (HAS), Clinical Research Hospital Program (PHRC), Interregional Delegation of Clinical Research (DIRC), Delegation of Clinical Research and Innovation (DRCi), and University Hospital Center (CHU). Dr Moore has acted as a consultant for AstraZeneca, Aventis, Baxter, Boots, GlaxoSmithKline, Helsinn, Novartis, Pfizer, Reckitt Benckiser, Roche, and other pharmaceutical companies. He holds no stock or other financial interest in any pharmaceutical company. Charles Pollack and Paul Butkerait are employees of Pfizer Consumer Healthcare. The authors report no other conflicts of interest in this work.

\section{References}

1. Naprelan ${ }^{\circledR}$ (naproxen sodium) [package insert]. San Diego, CA: Victory Pharma, Inc.; 2009.

2. Orudis ${ }^{\circledR}$ (ketoprofen) [package insert]. Philadelphia, PA: Wyeth Pharmaceuticals Inc.; 2007.

3. Hersh EV, Moore PA, Ross GL. Over-the-counter analgesics and antipyretics: a critical assessment. Clin Ther. 2000;22(5):500-548.

4. Schiff M, Minic M. Comparison of the analgesic efficacy and safety of nonprescription doses of naproxen sodium and Ibuprofen in the treatment of osteoarthritis of the knee. J Rheumatol. 2004;31(7):1373-1383.

5. Rainsford KD. Fifty years of ibuprofen: advancing pain and fever management. Int J Clin Pract Suppl. 2013;(178):1-2.

6. Cooper SA, Schachtel BP, Goldman E, Gelb S, Cohn P. Ibuprofen and acetaminophen in the relief of acute pain: a randomized, doubleblind, placebo-controlled study. J Clin Pharmacol. 1989;29(11): 1026-1030.

7. Schachtel BP, Fillingim JM, Thoden WR, Lane AC, Baybutt RI. Sore throat pain in the evaluation of mild analgesics. Clin Pharmacol Ther. 1988;44(6):704-711.

8. Rao P, Knaus EE. Evolution of nonsteroidal anti-inflammatory drugs (NSAIDs): cyclooxygenase (COX) inhibition and beyond. $J$ Pharm Pharm Sci. 2008;11(2):81s-110s.

9. Freedman MD. Drug interactions: classification and systematic approach. Am J Ther. 1995;2(6):433-443.

10. Haas DA. Adverse drug interactions in dental practice: interactions associated with analgesics, Part III in a series. J Am Dent Assoc. 1999; 130(3):397-407.

11. Duong M, Salvo F, Pariente A, et al. Usage patterns of 'over-thecounter' vs prescription-strength nonsteroidal anti-inflammatory drugs in France. Br J Clin Pharmacol. 2014;77(5):887-895.

12. Koffeman AR, Valkhoff VE, Celik S, et al. High-risk use of over-thecounter non-steroidal anti-inflammatory drugs: a population-based cross-sectional study. Br J Gen Pract. 2014;64(621):e191-e198.

13. Gutthann SP, García Rodríguez LA, Raiford DS. Individual nonsteroidal antiinflammatory drugs and other risk factors for upper gastrointestinal bleeding and perforation. Epidemiology. 1997;8(1):18-24.

14. Schoenfeld P, Kimmey MB, Scheiman J, Bjorkman D, Laine L. Review article: nonsteroidal anti-inflammatory drug-associated gastrointestinal complications - guidelines for prevention and treatment. Aliment Pharmacol Ther. 1999;13(10):1273-1285.

15. Henry D, Lim LL, Garcia Rodriguez LA, et al. Variability in risk of gastrointestinal complications with individual non-steroidal antiinflammatory drugs: results of a collaborative meta-analysis. $B M J$. 1996;312(7046):1563-1566.

16. Henry D, McGettigan P. Epidemiology overview of gastrointestinal and renal toxicity of NSAIDs. Int J Clin Pract Suppl. 2003;(135):43-49.

17. Derry S, Loke YK. Risk of gastrointestinal haemorrhage with long term use of aspirin: meta-analysis. BMJ. 2000;321(7270):1183-1187.

18. Weil J, Colin-Jones D, Langman M, et al. Prophylactic aspirin and risk of peptic ulcer bleeding. BMJ. 1995;310(6983):827-830.

19. Lewis SC, Langman MJ, Laporte JR, Matthews JN, Rawlins MD, Wiholm BE. Dose-response relationships between individual nonaspirin nonsteroidal anti-inflammatory drugs (NANSAIDs) and serious upper gastrointestinal bleeding: a meta-analysis based on individual patient data. Br J Clin Pharmacol. 2002;54(3):320-326.

20. Moore N, Vanganse E, Leparc J-M, et al. The PAIN study: Paracetamol, Aspirin and Ibuprofen New tolerability study: a large-scale, randomised clinical trial comparing the tolerability of aspirin, ibuprofen and paracetamol for short-term analgesia. Clin Drug Investig. 1999;18(2): 89-98.

21. Moore N, Charlesworth A, Van Ganse E, et al. Risk factors for adverse events in analgesic drug users: results from the PAIN study. Pharmacoepidemiol Drug Saf. 2003;12(7):601-610.

22. Fries JF, Bruce B. Rates of serious gastrointestinal events from low dose use of acetylsalicylic acid, acetaminophen, and ibuprofen in patients with osteoarthritis and rheumatoid arthritis. $J$ Rheumatol. 2003;30(10):2226-2233. 
23. Richy F, Bruyere O, Ethgen O, et al. Time dependent risk of gastrointestinal complications induced by non-steroidal anti-inflammatory drug use: a consensus statement using a meta-analytic approach. Ann Rheum Dis. 2004;63(7):759-766.

24. Blot WJ, McLaughlin JK. Over the counter non-steroidal antiinflammatory drugs and risk of gastrointestinal bleeding. J Epidemiol Biostat. 2000;5(2):137-142.

25. Lewis JD, Kimmel SE, Localio AR, et al. Risk of serious upper gastrointestinal toxicity with over-the-counter nonaspirin nonsteroidal anti-inflammatory drugs. Gastroenterology. 2005;129(6):1865-1874.

26. Hippisley-Cox J, Coupland C, Logan R. Risk of adverse gastrointestinal outcomes in patients taking cyclo-oxygenase-2 inhibitors or conventional non-steroidal anti-inflammatory drugs: population based nested case-control analysis. BMJ. 2005;331(7528):1310-1316.

27. Moore N, Salvo F, Duong M, Blin P, Pariente A. Cardiovascular risks associated with low-dose ibuprofen and diclofenac as used OTC. Expert Opin Drug Saf. 2014;13(2):167-179.

28. Summary Minutes of the Joint Arthritis Advisory Committee and Drug Safety and Risk Management Advisory Committee Meeting February 10-11, 2014. Silver Spring, MD: Food and Drug Administration; Center for Drug Evaluation and Research; 2014. Available from: http://www.fda.gov/downloads/AdvisoryCommittees/ CommitteesMeetingMaterials/Drugs/ArthritisAdvisoryCommittee/ UCM395527.pdf. Accessed September 10, 2014.

29. Advil ${ }^{\circledR}$ (ibuprofen) [package insert]. Madison, NJ: Pfizer Consumer Healthcare; 2012.

30. Aleve ${ }^{\circledR}$ (naproxen sodium) [package insert]. Whippany, NJ: Bayer HealthCare Consumer Care; 2014.

31. Safety Alerts for Human Medical Products: Vioxx (rofecoxib) Sep 2004 [webpage on the Internet]. Silver Spring, MD: U.S. Food and Drug Administration [updated August 21, 2013]. Available from: http:// www.fda.gov/Safety/MedWatch/SafetyInformation/SafetyAlertsforHumanMedicalProducts/ucm166532.htm. Accessed October 11, 2013.

32. Caldwell B, Aldington S, Weatherall M, Shirtcliffe P, Beasley R. Risk of cardiovascular events and celecoxib: a systematic review and metaanalysis. J R Soc Med. 2006;99(3):132-140.

33. Solomon DH, Avorn J, Stürmer T, Glynn RJ, Mogun H, Schneeweiss S. Cardiovascular outcomes in new users of coxibs and nonsteroida antiinflammatory drugs: high-risk subgroups and time course of risk Arthritis Rheum. 2006;54(5):1378-1389.

34. Fosbøl EL, Gislason GH, Jacobsen S, et al. Risk of myocardial infarction and death associated with the use of nonsteroidal anti-inflammatory drugs (NSAIDs) among healthy individuals: a nationwide cohort study. Clin Pharmacol Ther. 2009;85(2):190-197.

35. Hippisley-Cox J, Coupland C. Risk of myocardial infarction in patients taking cyclo-oxygenase-2 inhibitors or conventional non-steroidal antiinflammatory drugs: population based nested case-control analysis. BMJ. 2005;330(7504):1366.

36. Gislason GH, Rasmussen JN, Abildstrom SZ, et al. Increased mortality and cardiovascular morbidity associated with use of nonsteroidal anti-inflammatory drugs in chronic heart failure. Arch Intern Med. 2009;169(2):141-149.

37. Lipworth L, Friis S, Blot WJ, et al. A population-based cohort study of mortality among users of ibuprofen in Denmark. Am J Ther. 2004;11(3): $156-163$

38. Weir MR. Renal effects of nonselective NSAIDs and coxibs. Cleve Clin J Med. 2002;69 Suppl 1:SI53-SI58.

39. Farquhar WB, Morgan AL, Zambraski EJ, Kenney WL. Effects of acetaminophen and ibuprofen on renal function in the stressed kidney. J Appl Physiol (1985). 1999;86(2):598-604.

40. Schneider V, Lévesque LE, Zhang B, Hutchinson T, Brophy JM. Association of selective and conventional nonsteroidal antiinflammatory drugs with acute renal failure: a population-based, nested case-control analysis. Am J Epidemiol. 2006;164(9):881-889.

41. Furey SA, Vargas R, McMahon FG. Renovascular effects of nonprescription ibuprofen in elderly hypertensive patients with mild renal impairment. Pharmacotherapy. 1993;13(2):143-148.
42. Griffin MR, Yared A, Ray WA. Nonsteroidal antiinflammatory drugs and acute renal failure in elderly persons. Am J Epidemiol. 2000;151(5): 488-496.

43. Lesko SM, Mitchell AA. An assessment of the safety of pediatric ibuprofen. A practitioner-based randomized clinical trial. JAMA. 1995; 273(12):929-933

44. Lesko SM, Mitchell AA. Renal function after short-term ibuprofen use in infants and children. Pediatrics. 1997;100(6):954-957.

45. Ulinski T, Guigonis V, Dunan O, Bensman A. Acute renal failure after treatment with non-steroidal anti-inflammatory drugs. Eur J Pediatr. 2004;163(3):148-150

46. Wong W, Coward RJ, Morris MC. Ibuprofen induced acute renal failure in an infant. $N Z$ Med J. 2001;114(1140):431.

47. Kovesi TA, Swartz R, MacDonald N. Transient renal failure due to simultaneous ibuprofen and aminoglycoside therapy in children with cystic fibrosis. N Engl J Med. 1998;338(1):65-66.

48. Volans G, Monaghan J, Colbridge M. Ibuprofen overdose. Int J Clin Pract Suppl. 2003;(135):54-60.

49. Veltri JC, Rollins DE. A comparison of the frequency and severity of poisoning cases for ingestion of acetaminophen, aspirin, and ibuprofen. Am J Emerg Med. 1988;6(2):104-107.

50. Palmer R, Weiss R, Zusman RM, Haig A, Flavin S, MacDonald B. Effects of nabumetone, celecoxib, and ibuprofen on blood pressure control in hypertensive patients on angiotensin converting enzyme inhibitors. Am J Hypertens. 2003;16(2):135-139.

51. Gurwitz JH, Everitt DE, Monane M, et al. The impact of ibuprofen on the efficacy of antihypertensive treatment with hydrochlorothiazide in elderly persons. J Gerontol A Biol Sci Med Sci. 1996;51(2): M74-M79.

52. Houston MC, Weir M, Gray J, et al. The effects of nonsteroidal anti-inflammatory drugs on blood pressures of patients with hypertension controlled by verapamil. Arch Intern Med. 1995;155(10): 1049-1054.

53. Bhagat K. Effects of non-steroidal anti-inflammatory drugs on hypertension control using angiotensin converting enzyme inhibitors and thiazide diuretics. East Afr Med J. 2001;78(10):507-509.

54. Thakur V, Cook ME, Wallin JD. Antihypertensive effect of the combination of fosinopril and HCTZ is resistant to interference by nonsteroidal antiinflammatory drugs. Am J Hypertens. 1999;12(9 Pt 1): 925-928.

55. MacDonald TM, Richard D, Lheritier K, Krammer G. The effects of lumiracoxib $100 \mathrm{mg}$ once daily vs ibuprofen $600 \mathrm{mg}$ three times daily on the blood pressure profiles of hypertensive osteoarthritis patients taking different classes of antihypertensive agents. Int J Clin Pract. 2010; 64(6):746-755.

56. Lapi F, Azoulay L, Yin H, Nessim SJ, Suissa S. Concurrent use of diuretics, angiotensin converting enzyme inhibitors, and angiotensin receptor blockers with non-steroidal anti-inflammatory drugs and risk of acute kidney injury: nested case-control study. BMJ. 2013;346:e8525.

57. Pavlicević I, Glavaski M, Rumboldt M, Rumboldt Z. Prohypertensive effects of non-steroidal anti-inflammatory drugs are mostly due to vasoconstriction. Coll Antropol. 2011;35(3):817-822.

58. Ayalasomayajula S, Tchaloyan S, Yeh CM, et al. A study of the pharmacokinetic interactions of the direct renin inhibitor aliskiren with allopurinol, celecoxib and cimetidine in healthy subjects. Curr Med Res Opin. 2008;24(3):717-726.

59. Verhamme K, Mosis G, Dieleman J, Stricker B, Sturkenboom M. Spironolactone and risk of upper gastrointestinal events: population based case-control study. BMJ. 2006;333(7563):330.

60. Masclee GM, Valkhoff VE, Coloma PM, et al. Risk of upper gastrointestinal bleeding from different drug combinations. Gastroenterology. 2014;147(4):784-792.

61. Hoffmann W, van den Berg N, Thyrian JR, Fiss T. Frequency and determinants of potential drug-drug interactions in an elderly population receiving regular home visits by GPs - results of the home medication review in the AGnES-studies. Pharmacoepidemiol Drug Saf. 2011; 20(12):1311-1318. 
62. Klassen D, Goodfriend TL, Schuna AA, Young DY, Peterson CA. Assessment of blood pressure during treatment with naproxen or ibuprofen in hypertensive patients treated with hydrochlorothiazide. J Clin Pharmacol. 1993;33(10):971-978.

63. Pavlicević I, Kuzmanić M, Rumboldt M, Rumboldt Z. Interaction between antihypertensives and NSAIDs in primary care: a controlled trial. Can J Clin Pharmacol. 2008;15(3):e372-e382.

64. Paterson CA, Jacobs D, Rasmussen S, Youngberg SP, McGuinness N. Randomized, open-label, 5-way crossover study to evaluate the pharmacokinetic/pharmacodynamic interaction between furosemide and the non-steroidal anti-inflammatory drugs diclofenac and ibuprofen in healthy volunteers. Int J Clin Pharmacol Ther. 2011;49(8):477-490.

65. Webster J. Interactions of NSAIDs with diuretics and beta-blockers mechanisms and clinical implications. Drugs. 1985;30(1):32-41.

66. Davies JG, Rawlins DC, Busson M. Effect of ibuprofen on blood pressure control by propranolol and bendrofluazide. J Int Med Res. 1988; 16(3):173-181.

67. Grover SA, Coupal L, Zowall H. Treating osteoarthritis with cyclooxygenase-2-specific inhibitors: what are the benefits of avoiding blood pressure destabilization? Hypertension. 2005;45(1):92-97.

68. Catella-Lawson F, Reilly MP, Kapoor SC, et al. Cyclooxygenase inhibitors and the antiplatelet effects of aspirin. NEngl J Med. 2001;345(25): 1809-1817.

69. Mackenzie IS, Coughtrie MW, MacDonald TM, Wei L. Antiplatelet drug interactions. J Intern Med. 2010;268(6):516-529.

70. Saxena A, Balaramnavar VM, Hohlfeld T, Saxena AK. Drug/drug interaction of common NSAIDs with antiplatelet effect of aspirin in human platelets. Eur J Pharmacol. 2013;721(1-3):215-224.

71. Kimmel SE, Berlin JA, Reilly M, et al. The effects of nonselective non-aspirin non-steroidal anti-inflammatory medications on the risk of nonfatal myocardial infarction and their interaction with aspirin. J Am Coll Cardiol. 2004;43(6):985-990.

72. Kurth T, Glynn RJ, Walker AM, et al. Inhibition of clinical benefits of aspirin on first myocardial infarction by nonsteroidal antiinflammatory drugs. Circulation. 2003;108(10):1191-1195.

73. MacDonald TM, Wei L. Effect of ibuprofen on cardioprotective effect of aspirin. Lancet. 2003;361(9357):573-574.

74. Patel TN, Goldberg KC. Use of aspirin and ibuprofen compared with aspirin alone and the risk of myocardial infarction. Arch Intern Med. 2004;164(8):852-856

75. Fischer LM, Schlienger RG, Matter CM, Jick H, Meier CR. Current use of nonsteroidal antiinflammatory drugs and the risk of acute myocardial infarction. Pharmacotherapy. 2005;25(4):503-510.

76. Antonicelli L, Tagliabracci A. Asthma death induced by ibuprofen. Monaldi Arch Chest Dis. 1995;50(4):276-278.

77. Goraya JS, Virdi VS. To the editor: Exacerbation of asthma by ibuprofen in a very young child. Pediatr Pulmonol. 2001;32(3):262.

78. Merritt GJ, Selle RI Jr. Cross-reactivity between aspirin and ibuprofen in an asthmatic - a case report. Am J Hosp Pharm. 1978;35(10): $1245-1248$.

79. Szczeklik A, Nizankowska E, Mastalerz L, Szabo Z. Analgesics and asthma. Am J Ther. 2002;9(3):233-243.

80. Palmer GM. A teenager with severe asthma exacerbation following ibuprofen. Anaesth Intensive Care. 2005;33(2):261-265.

81. Debley JS, Carter ER, Gibson RL, Rosenfeld M, Redding GJ. The prevalence of ibuprofen-sensitive asthma in children: a randomized controlled bronchoprovocation challenge study. J Pediatr. 2005;147(2): 233-238.

82. Mellemkjaer L, Blot WJ, Sørensen HT, et al. Upper gastrointestinal bleeding among users of NSAIDs: a population-based cohort study in Denmark. Br J Clin Pharmacol. 2002;53(2):173-181.

83. Johnsen SP, Sørensen HT, Mellemkjoer L, et al. Hospitalisation for upper gastrointestinal bleeding associated with use of oral anticoagulants. Thromb Haemost. 2001;86(2):563-568.

84. Hirsh J, Dalen JE, Deykin D, Poller L. Oral anticoagulants. Mechanism of action, clinical effectiveness, and optimal therapeutic range. Chest. 1992;102(4 Suppl):312S-326S.
85. P450 Drug Interaction Table [webpage on the Internet]. Indianapolis, IN: Indiana University [updated July 12, 2013; cited April 12, 2013 ]. Available from: http://medicine.iupui.edu/clinpharm/ddis/table.aspx. Accessed March 21, 2015.

86. Greenblatt DJ, von Moltke LL. Interaction of warfarin with drugs, natural substances, and foods. J Clin Pharmacol. 2005;45(2):127-132.

87. Thijssen HH, Soute BA, Vervoort LM, Claessens JG. Paracetamol (acetaminophen) warfarin interaction: NAPQI, the toxic metabolite of paracetamol, is an inhibitor of enzymes in the vitamin $\mathrm{K}$ cycle. Thromb Haemost. 2004;92(4):797-802.

88. Mahé I, Caulin C, Bergmann JF. Does paracetamol potentiate the effects of oral anticoagulants?: a literature review. Drug Saf. 2004; 27(5):325-333.

89. Mahé I, Bertrand N, Drouet L, et al. Paracetamol: a haemorrhagic risk factor in patients on warfarin. Br J Clin Pharmacol. 2005;59(3): 371-374.

90. Mahé I, Bertrand N, Drouet L, et al. Interaction between paracetamol and warfarin in patients: a double-blind, placebo-controlled, randomized study. Haematologica. 2006;91(12):1621-1627.

91. Zhang Q, Bal-dit-Sollier C, Drouet L, et al. Interaction between acetaminophen and warfarin in adults receiving long-term oral anticoagulants: a randomized controlled trial. Eur J Clin Pharmacol. 2011;67(3):309-314.

92. MacDonald TM, Wei L. Is there an interaction between the cardiovascular protective effects of low-dose aspirin and ibuprofen? Basic Clin Pharmacol Toxicol. 2006;98(3):275-280.

93. Information for Healthcare Professionals: Concomitant use of Ibuprofen and Aspirin [webpage on the Internet]. Silver Spring, MD: U.S. Food and Drug Administration; 2006 [updated August 14, 2013; cited April 12, 2013]. Available from: http:/www.fda.gov/Drugs/DrugSafety/PostmarketDrugSafetyInformationforPatientsandProviders/ ucm125222.htm. Accessed March 21, 2015.

94. Serebruany VL. Selective serotonin reuptake inhibitors and increased bleeding risk: are we missing something? Am J Med. 2006;119(2): 113-116.

95. Hallbäck I, Hägg S, Eriksson AC, Whiss PA. In vitro effects of serotonin and noradrenaline reuptake inhibitors on human platelet adhesion and coagulation. Pharmacol Rep. 2012;64(4):979-983.

96. Bismuth-Evenzal Y, Gonopolsky Y, Gurwitz D, Iancu I, Weizman A, Rehavi M. Decreased serotonin content and reduced agonist-induced aggregation in platelets of patients chronically medicated with SSRI drugs. J Affect Disord. 2012;136(1-2):99-103.

97. de Abajo FJ, Rodríguez LA, Montero D. Association between selective serotonin reuptake inhibitors and upper gastrointestinal bleeding: population based case-control study. BMJ. 1999;319(7217): 1106-1109.

98. de Jong JC, van den Berg PB, Tobi H, de Jong-van den Berg LT. Combined use of SSRIs and NSAIDs increases the risk of gastrointestinal adverse effects. Br J Clin Pharmacol. 2003;55(6):591-595.

99. Schafer AI. Effects of nonsteroidal antiinflammatory drugs on platelet function and systemic hemostasis. J Clin Pharmacol. 1995;35(3): 209-219.

100. Zullino DF, Khazaal Y. Increased risk of gastrointestinal adverse effects under SSRI/NSAID combination may be due to pharmacokinetic interactions. Br J Clin Pharmacol. 2005;59(1):118-119.

101. Andrade C, Sandarsh S, Chethan KB, Nagesh KS. Serotonin reuptake inhibitor antidepressants and abnormal bleeding: a review for clinicians and a reconsideration of mechanisms. J Clin Psychiatry. 2010;71(12): 1565-1575.

102. Phelan KM, Mosholder AD, Lu S. Lithium interaction with the cyclooxygenase 2 inhibitors rofecoxib and celecoxib and other nonsteroidal anti-inflammatory drugs. J Clin Psychiatry. 2003;64(11): $1328-1334$.

103. Finley PR, Warner MD, Peabody CA. Clinical relevance of drug interactions with lithium. Clin Pharmacokinet. 1995;29(3):172-191.

104. Ragheb M, Powell AL. Lithium interaction with sulindac and naproxen. J Clin Psychopharmacol. 1986;6(3):150-154. 
105. Ragheb M. Ibuprofen can increase serum lithium level in lithiumtreated patients. J Clin Psychiatry. 1987;48(4):161-163.

106. Kaufman DW, Kelly JP, Wiholm BE, et al. The risk of acute major upper gastrointestinal bleeding among users of aspirin and ibuprofen at various levels of alcohol consumption. Am J Gastroenterol. 1999; 94(11):3189-3196.

107. Food and Drug Administration, HHS. Organ-specific warnings; internal analgesic, antipyretic, and antirheumatic drug products for overthe-counter human use; final monograph. Final rule. Fed Regist. 2009; 74(81):19385-19409.

108. Müller WE, Singer A, Wonnemann M, Hafner U, Rolli M, Schäfer C. Hyperforin represents the neurotransmitter reuptake inhibiting constituent of hypericum extract. Pharmacopsychiatry. 1998;31 Suppl 1: $16-21$.

109. Borrelli F, Izzo AA. Herb-drug interactions with St John's wort (Hypericum perforatum): an update on clinical observations. AAPSJ. 2009;11(4):710-727.

110. Bell EC, Ravis WR, Lloyd KB, Stokes TJ. Effects of St John's wort supplementation on ibuprofen pharmacokinetics. Ann Pharmacother. 2007;41(2):229-234.

111. Izzo AA, Ernst E. Interactions between herbal medicines and prescribed drugs: an updated systematic review. Drugs. 2009;69(13): 1777-1798.

112. Meisel C, Johne A, Roots I. Fatal intracerebral mass bleeding associated with Ginkgo biloba and ibuprofen. Atherosclerosis. 2003; 167(2):367.

113. Savovic J, Wider B, Ernst E. Effects of Ginkgo biloba on blood coagulation parameters: a systematic review of randomised clinical trials. Evidence-Based Integrative Medicine. 2005;2(3):167-176.

114. Chavez ML, Jordan MA, Chavez PI. Evidence-based drug - herbal interactions. Life Sci. 2006;78(18):2146-2157.

115. Methotrexate sodium [package insert]. Lake Zurich, IL: Fresenlus Kabi USA, LLC; 2013.

116. Tracy TS, Krohn K, Jones DR, Bradley JD, Hall SD, Brater DC. The effects of a salicylate, ibuprofen, and naproxen on the disposition of methotrexate in patients with rheumatoid arthritis. Eur J Clin Pharmacol. 1992;42(2):121-125.

117. Kremer JM, Hamilton RA. The effects of nonsteroidal antiinflammatory drugs on methotrexate (MTX) pharmacokinetics: impairment of renal clearance of MTX at weekly maintenance doses but not at $7.5 \mathrm{mg}$. J Rheumatol. 1995;22(11):2072-2077.

118. Egan LJ. Drug interactions in gastroenterology: mechanisms, consequences, and how to avoid. Clin Gastroenterol Hepatol. 2004;2(9): 725-730.

119. Murray MD, Black PK, Kuzmik DD, et al. Acute and chronic effects of nonsteroidal antiinflammatory drugs on glomerular filtration rate in elderly patients. Am J Med Sci. 1995;310(5):188-197.

120. Brooks CD, Ulrich JE. Effect of ibuprofen or aspirin on probenecidinduced uricosuria. J Int Med Res. 1980;8(4):283-285.
121. García Rodríguez LA, Egan K, FitzGerald GA. Traditional nonsteroidal anti-inflammatory drugs and postmenopausal hormone therapy: a drug-drug interaction? PLoS Med. 2007;4(5):e157.

122. Heiss G, Wallace R, Anderson GL, et al; WHI Investigators. Health risks and benefits 3 years after stopping randomized treatment with estrogen and progestin. JAMA. 2008;299(9):1036-1045.

123. Rossouw JE, Anderson GL, Prentice RL, et al; Writing Group for the Women's Health Initiative Investigators. Risks and benefits of estrogen plus progestin in healthy postmenopausal women: principal results from the Women's Health Initiative randomized controlled trial. JAMA. 2002;288(3):321-333.

124. Manson JE, Chlebowski RT, Stefanick ML, et al. Menopausal hormone therapy and health outcomes during the intervention and extended poststopping phases of the Women's Health Initiative randomized trials. JAMA. 2013;310(13):1353-1368.

125. Schierbeck LL, Rejnmark L, Tofteng CL, et al. Effect of hormone replacement therapy on cardiovascular events in recently postmenopausal women: randomised trial. BMJ. 2012;345:e6409.

126. Mendonça LL, Khamashta MA, Nelson-Piercy C, Hunt BJ, Hughes GR. Non-steroidal anti-inflammatory drugs as a possible cause for reversible infertility. Rheumatology (Oxford). 2000;39(8):880-882.

127. Nielsen GL, Sørensen HT, Larsen H, Pedersen L. Risk of adverse birth outcome and miscarriage in pregnant users of non-steroidal anti-inflammatory drugs: population based observational study and case-control study. BMJ. 2001;322(7281):266-270.

128. Nielsen GL, Skriver MV, Pedersen L, Sørensen HT. Danish group reanalyses miscarriage in NSAID users. BMJ. 2004;328(7431):109.

129. Horwitz RI, Feinstein AR. The problem of "protopathic bias" in casecontrol studies. Am J Med. 1980;68(2):255-258.

130. Li DK, Liu L, Odouli R. Exposure to non-steroidal anti-inflammatory drugs during pregnancy and risk of miscarriage: population based cohort study. BMJ. 2003;327(7411):368.

131. Majed BH, Khalil RA. Molecular mechanisms regulating the vascular prostacyclin pathways and their adaptation during pregnancy and in the newborn. Pharmacol Rev. 2012;64(3):540-582.

132. Piper JM, Ray WA, Daugherty JR, Griffin MR. Corticosteroid use and peptic ulcer disease: role of nonsteroidal anti-inflammatory drugs. Ann Intern Med. 1991;114(9):735-740.

133. Kataoka H, Horie Y, Koyama R, Nakatsugi S, Furukawa M. Interaction between NSAIDs and steroid in rat stomach: safety of nimesulide as a preferential COX-2 inhibitor in the stomach. Dig Dis Sci. 2000;45(7):1366-1375.

134. Jacubeit T, Drisch D, Weber E. Risk factors as reflected by an intensive drug monitoring system. Agents Actions Suppl. 1990;29:117-125.

135. LaFleur J, McBeth C, Gunning K, Oderda L, Steinvoort C, Oderda GM. Prevalence of drug-related problems and cost-savings opportunities in medicaid high utilizers identified by a pharmacist-run drug regimen review center. J Manag Care Pharm. 2006;12(8):677-685.
Therapeutics and Clinical Risk Management

\section{Publish your work in this journal}

Therapeutics and Clinical Risk Management is an international, peerreviewed journal of clinical therapeutics and risk management, focusing on concise rapid reporting of clinical studies in all therapeutic areas, outcomes, safety, and programs for the effective, safe, and sustained use of medicines. This journal is indexed on PubMed Central, CAS,

\section{Dovepress}

EMBase, Scopus and the Elsevier Bibliographic databases. The manuscript management system is completely online and includes a very quick and fair peer-review system, which is all easy to use. Visit http://www.dovepress.com/testimonials.php to read real quotes from published authors. 